\title{
Thermochemical Seasonal Energy Storage for Solar Thermal Power
}

J. S. Barnhart

January 1984

Prepared for the U.S. Department of Energy under Contract DE-AC06-76RLO 1830

Pacific Northwest Laboratory Operated for the U.S. Department of Energy by Battelle Memorial Institute 


\title{
DISCLAIMER
}

This report was prepared as an account of work sponsored by an agency of the United States Government. Neither the United States Government nor any agency thereof, nor any of their employees, makes any warranty, express or implied, or assumes any legal liability or responsibility for the accuracy, completeness, or usefulness of any information, apparatus, product, or process disclosed, or represents that its use would not infringe privately owned rights. Reference herein to any specific commercial product, process, or service by trade name, trademark, manufacturer, or otherwise, does not necessarily constitute or imply its endorsement, recommendation, or favoring by the United States Government or any agency thereof. The views and opinions of authors expressed herein do not necessarily state or reflect those of the United States Government or any agency thereof.

\author{
PACIFIC NORTHWEST LABORATORY \\ operated by \\ BATTELLE \\ for the \\ UNITED STATES DEPARTMENT OF ENERGY \\ under Contract DE-AC06-76RLO 1830
}

\begin{tabular}{|c|c|}
\hline \multicolumn{2}{|c|}{ Printed in the United States of America } \\
\hline$A$ & tion Service \\
\hline $\begin{array}{l}\text { National Tecl } \\
\text { United States }\end{array}$ & $\begin{array}{l}\text { tion Service } \\
\text { f Commerce }\end{array}$ \\
\hline 5285 & pad \\
\hline & \\
\hline & \\
\hline & \\
\hline Pages & $\begin{array}{l}\text { Price } \\
\text { Codes }\end{array}$ \\
\hline $001-025$ & $\mathrm{~A} 02$ \\
\hline $026-050$ & $\mathrm{~A} 03$ \\
\hline 051-075 & $\mathrm{A} 04$ \\
\hline $076-100$ & A05 \\
\hline $101-125$ & $\mathrm{~A} 06$ \\
\hline $126-150$ & $\mathrm{~A} 07$ \\
\hline $151-175$ & $A 08$ \\
\hline $176-200$ & $\mathrm{~A} 09$ \\
\hline $201-225$ & A010 \\
\hline $226-250$ & A011 \\
\hline $251-275$ & A012 \\
\hline $276-300$ & A013 \\
\hline
\end{tabular}


THERMOCHEMICAL SEASONAL ENERGY STORAGE FOR SOLAR THERMAL POWER

J. S. Barnhart

January 1984

Prepared for the U.S. Department of Energy under Contract DE-AC06-76RLO 1830

Pacific Northwest Laboratory Richland, Washington 99352 


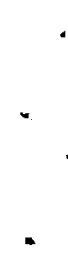


Seasonal thermal energy storage (STES) involves storing thermal energy, such as winter chill, summer heat, and industrial waste heat, for future use in heating and cooling buildings or industrial processes. Widespread development and implementation of STES would significantly reduce the need to generate primary energy in the U.S. In fact, 1980 data indicate that STES is suitable for providing 5 to $10 \%$ of the nation's energy with major contributions in the commerical, industrial, and residential sectors.

This report examines the use of seasonal thermochemical energy storage to provide uninterrupted electric power from solar thermal power plants. Thermochemical energy storage uses reversible chemical reactions to store energy in chemical species for long time periods at ambient temperature. Thermochemical storage is therefore appropriate for seasonal applications because energy loss with time is negligible. The seasonal variation in insolation makes long-term storage a necessity if true baseload power is to be provided by solar thermal plants.

Land is D. Kannberg, Manager Underground Energy Storage Program 


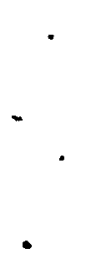


During the many years that thermochemical energy storage has been under investigation, the concept has been plagued with two persistent problems: high capital cost and poor efficiency. Literally hundreds of chemical reactions have been scrutinized, many in great depth. Sophisticated systems analyses have also been carried out. For short-term storage, thermochemical systems suffer in comparison with highly efficient sensible storage media such as molten salts. Long-term storage, on the other hand, is not cost-competitive with systems employing fossil backup power.

Thermochemical storage will play a significant role in solar thermal electric conversion only under highly select circumstances. The portion of electric demand served by solar plants must be sufficiently high that the balance of the grid cannot fully supplant seasonal storage. High fossil fuel costs must preclude the use of gas turbines for backup power. Significant breakthroughs in the development of one or more chemical reaction systems must occur. Ingeniously integrated systems must be employed to enhance the efficiency and cost-effectiveness of thermochemical storage. A promising integration scheme discussed herein consists of using sensible storage for diurnal cycling in parallel with thermochemical seasonal storage. Under the most favorable circumstances, thermochemical storage can be expected to play a small but perhaps vital role in supplying baseload energy from solar thermal electric conversion plants. 



\section{CONTENTS}

FOREWORD ................................ $i$... SUMMARY. .................... $1.0 \quad$ INTRODUCTION. . . . . . . . . . . . . . . . . 1.1

2.0 CHEMICAL ENERGY STORAGE PROCESS DESCRIPTIONS. . . . . . . 2.1 2.1 FUNCTIONAL CRITERIA. . . . . . . . . . . . 2.1 2.2 CANDIDATE REACTIONS. . . . . . . . . . . . . . . . . 2.4 3.0 Alternatives to CHEMICAL ENERGY StORAgE . . . . . . . . . . . 3.1 4.0 THE FUtURe OF CHEMiCAl ENERGY STORAGE . . . . . . . . . . . 4.1 REFERENCES ..................... R. . . . . APPENDIX - COMBINED CHEMICAL/SENSIBLE STORAGE CONCEPT FOR SEASONAL APPLICATIONS. . . . . . . . . . . . . . A.I 

THERMOCHEMICAL SEASONAL ENERGY STORAGE FOR SOLAR THERMAL POWER

\subsection{INTRODUCTION}

The diurnal and seasonal variations in insolation have proved to be major impediments to the development of solar thermal electric conversion (STEC) plants. Under the best of circumstances, STEC plants can be expected to provide energy directly from the sun only about $40 \%$ of the time. This situation is tolerable if the balance of the utility grid contains sufficient reserves to meet the demand at night and during cloudy periods. Clearly, however, some means of enhancing the capacity factor of STEC plants must be implemented if they are ever to supply a significant fraction of demand in a given locale.

Thermochemical energy storage (or simply chemical energy storage, CES) has been studied extensively as a means of storing solar energy during daylight hours for subsequent use at night and during extended periods of solar occultation. In contrast to sensible storage systems, which store energy by virtue of their high temperatures, CES systems store energy in chemical species at ambient temperature. The absence of sensible heat loss plus the negligible rate of chemical reaction at ambient temperature imply that energy can be stored indefinitely without significant loss.

Unfortunately, practical considerations have arisen to severely deflate the early promise of CES systems. Cycle efficiencies have proved very disappointing, typically ranging from 30 to $50 \%$. Chemical reactors for even the most straightforward systems are complex and expensive. Furthermore, many of the most promising systems require the storage of gaseous chemical species at high pressures, a further economic disincentive. Sensible systems, on the other hand, have proved to be highly efficient and cost-effective for short-term (up to perhaps $50 \mathrm{~h}$ ) storage. Thus, CES systems will probably be limited to seasonal applications if they prove at all feasible. 
The current state of CES system development is presented in Section 2 of this document. Functional criteria for CES systems are described and then used to characterize three of the more promising chemical systems. Alternatives to chemical storage are presented in Section 3. Included among these is a proposed chemical-sensible hybrid storage system proposed by Iannucci that may well be the best hope for CES systems. Conclusions regarding the future role of chemical storage in STEC plants are presented in Section 4 . 


\subsection{CHEMICAL ENERGY STORAGE PROCESS DESCRIPTIONS}

Considering the many thousands of chemical reactions used routinely in the industrialized world, one could well imagine that the discovery of the ideal reaction for CES applications is only a matter of time. In fact, the rather severe bounds imposed by cost, temperature, and freedom from detrimental side reactions limit the choices to a mere handful, relatively speaking. Smith (1979) performed an exhaustive study of candidate reactions, beginning with more than 500 and systematically eliminating until only 9 remained. Two of these reactions are described in this section: 1) $\mathrm{SO}_{2}+1 / 2 \mathrm{O}_{2} \rightarrow \mathrm{SO}_{3}$ and 2) $\mathrm{CaO}+\mathrm{H}_{2} \mathrm{O} \rightarrow \mathrm{Ca}(\mathrm{OH})_{2}$. A third reaction cited frequently in the literature (and eliminated by Smith) is also discussed: $\mathrm{CO}+3 \mathrm{H}_{2} \rightarrow \mathrm{H}_{2} \mathrm{O}+\mathrm{CH}_{4}$. First, however, functional criteria by which CES systems can be compared are presented.

\subsection{FUNCTIONAL CRITERIA}

Appropriate functional criteria for evaluating CES systems are listed in Table 2.1. As noted in Table 2.1, the criteria are arranged in three groups, to be discussed in turn: thermal, economic, and chemical.

The endothermic reaction temperature is the temperature at which the low-energy chemical species are converted to high-energy species. This reaction is endothermic in the sense that a net energy input is required. Endothermic reactions are frequently catalyzed to increase the reaction rate and allow the reaction to proceed at a lower temperature.

The exothermic reaction temperature is the temperature at which energy is liberated from the CES system. For most systems, the exothermic reaction occurs at a significantly lower temperature than the endothermic reaction. Smith (1979) quantified the resulting loss of availability as the ratio of Carnot efficiencies corresponding to the endothermic and exothermic reaction temperatures. 
TABLE 2.1. Functional Criteria for Chemical Energy Storage Systems

Category

Therma 1

Economic

Chemical
Criterion

Endothermic reaction temperature

Exothermic reaction temperature

Round-trip efficiency

Energy storage density

Storage pressure

$\left\{\begin{array}{l}\text { Capital cost } \\ \text { Utilization factor } \\ \text { Extent of systems integration }\end{array}\right.$

$\left\{\begin{array}{l}\text { Catalyst requirements } \\ \text { Materials constraints } \\ \text { Freedom from undesirable side reactions }\end{array}\right.$

The round-trip efficiency is the product of the storage system charging and discharging efficiencies, defined by Smith (1979) as

$$
n_{R T}=\Sigma q_{d} /\left(\Sigma q_{c}+\Sigma w_{c}\right)
$$

where $\quad n_{R T}=$ the round-trip efficiency

$\Sigma q_{d}=$ sum of heat outputs available to the power cycle

$\Sigma q_{c}=$ sum of heat inputs to charging

$\Sigma w_{C}=$ sum of the thermal equivalents of mechanical work inputs to charging

Round-trip efficiencies for the most promising systems studied by Smith ranged from 20 to $50 \%$. Heat exchange proved to be a major source of inefficiency, correctable only at disproportionate expense. 
Energy storage density is the amount of recoverable energy stored per unit volume. Bramlette (1979) reports that CES systems exhibit energy densities of two to ten times as great as those of sensible storage systems. However, many otherwise promising CES systems require the storage of one or more gaseous species at high pressure, greatly increasing capital and operating expenses. Underground storage of gaseous species may reduce capital costs, but only for relatively large storage volumes at favorable sites.

Capital cost is dominant among the economic criteria, particularly for those systems requiring gas storage. The utilization factor may be loosely defined as the number of times a given portion of storage is discharged in a year. The first $10 \mathrm{~h}$ of storage, (a) for example, are discharged every night and thus are very cost-effective. The balance of storage unfortunately sees a much lower utilization factor and is correspondingly less valuable. Iannucci, Fish and Bramlette (1979) report that, for a 100-h storage system in Albuquerque, the first $10 \mathrm{~h}$ of storage are thirty times more valuable than the last $90 \mathrm{~h}$ on a per-hour-of-storage basis.

The extent of systems integration criterion reflects the opportunity to reduce capital cost and increase round-trip efficiency by integrating the CES system with the balance of plant. Process heat needs, for example, may be fulfilled inexpensively with turbine extraction steam from a Rankine cycle. Waste heat streams from the CES system might correspondingly be used cost-effectively elsewhere.

The chemical complexities of CES systems are reflected in the three remaining criteria. Many of the candidate systems require catalysts, which have proved susceptible to physical degradation and poisoning with undesirable byproducts. Materials constraints for reactor and storage

(a) An hour of storage is defined to be that amount required to operate the turbogenerator at an output equivalent to the plant nameplate rating for $1 \mathrm{~h}$. 
vessels arise from the extreme corrosiveness of many chemical species. Undesirable side reactions are particularly prevalent in systems involving hydrocarbon species and lead to two problems just mentioned: catalyst poisoning and vessel corrosion.

\subsection{CANDIDATE REACTIONS}

Three of the most promising chemical reaction systems identified from the literature are briefly described here. Each has been the subject of exhaustive study; nevertheless, significant obstacles remain to be addressed before any of the systems can be demonstrated on an industrial scale.

The reversible oxidation of sulfur dioxide via the following reaction has received perhaps more attention than any other reaction for thermochemical storage:

$$
\mathrm{SO}_{2}+1 / 2 \mathrm{O}_{2} \rightarrow \mathrm{SO}_{3}
$$

Smith (1979) cites endothermic and exothermic reaction temperatures of 1100 and $1089^{\circ} \mathrm{K}$; Stewart (1979), however, presents corresponding values of 1100 and $800^{\circ} \mathrm{K}$, respectively. (Note that exothermic temperatures equal to the endothermic values are thermodynamically possible but are often not economically justifiable.) A high-temperature catalyst is required for the endothermic reaction. The reaction involves only two elements and is relatively free of deleterious side reactions. Smith reports a round-trip efficiency of $33 \%$, while Stewart's value (under markedly different ground rules) is $16.4 \%$. Energy storage cos.ts are very high because of the presence of gaseous $\mathrm{O}_{2}$.

A reaction discounted by Smith (1979) but still occasionally under investigation (Nix 1982) is:

$$
\mathrm{CO}+3 \mathrm{H}_{2} \rightarrow \mathrm{CH}_{4}+\mathrm{H}_{2} \mathrm{O}
$$


Both Nix and Stewart (1979) examined this system primarily for energy transport rather than storage. Endothermic and exothermic reaction temperatures of 1100 and $700^{\circ} \mathrm{K}$ are cited by both Smith and Stewart; Stewart reports a rather favorable round-trip efficiency of $29 \%$. A probably insurmountable obstacle to the use of this system for seasonal storage is the need to store three gaseous species: $\mathrm{CO}, \mathrm{H}_{2}$, and $\mathrm{CH}_{4}$.

Perhaps the most promising of the three reactions discussed herein is

$$
\mathrm{CaO}+\mathrm{H}_{2} \mathrm{O} \rightarrow \mathrm{Ca}(\mathrm{OH})_{2}
$$

The endothermic and exothermic reaction temperatures are relatively modest: 800 and $675^{\circ} \mathrm{K}$, respectively (Smith 1979). Smith reports a round-trip efficiency of 35\%. However, neither reaction is catalytic, and none of the reactants is gaseous at ambient temperature. The reactor design is very complex, however, because of the solid CaO. Heat recovery from this species and its long-term survival are both at issue. Bramlette (1979) reports that repeated cycling through reaction (2.4) decreased the amount of water that could be reacted with the original $\mathrm{CaO}$ to only $34 \%$ of the initial value after 140 cycles. Clearly, neither this reaction nor the previous two can be considered ready for implementation. 


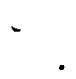

- 


\subsection{ALTERNATIVES TO CHEMICAL ENERGY STORAGE}

Solar thermal electric conversion (STEC) plants may eventually become so plentiful that utility planners will insist that any new facilities be built as autonomous plants. An autonomous plant is one that can produce its nameplate rating continually for a full year, issues of reliability aside (Smith 1979). Chemical energy storage systems can then be expected to play a significant role in providing power during periods of low insolation. It is appropriate, however, to discuss power supply options under requirements short of full autonomy to point out the obstacles faced by CES systems in the near term.

Industrialized countries with well-developed electrical grids supplied by diverse resources currently have little or no need for solar energy storage of any kind. The very modest output from this nation's STEC plants over the next 10 years or more will scarcely be noticed on a grid-wide basis. Furthermore, STEC plants will be located predominantly in regions exhibiting peak demand during daylight summer hours. This fortuitous matching of supply and demand further reduces the need for energy storage.

By far, the most cost-effective role for solar energy storage will be to supply power at night. The unfailing diurnal cycle guarantees that the first 10 to $15 \mathrm{~h}$ of storage will be used at least 365 times a year; cloud passage will increase that number sti11 further. Iannucci (1981) reports that roughly $85 \%$ of demand for a baseload plant can be met by a STEC plant with $20 \mathrm{~h}$ of storage for an Albuquerque location. Storage requirements of such short duration can be met more economically with sensible rather than chemical storage. The remaining 15\% of demand occurs during periods of extended solar occultation and represents the only apparent niche for CES systems. Of course, the possibility of supplying that $15 \%$ of demand from non-solar resources may completely eliminate the need for chemical storage.

Assuming, however, that a fully autonomous STEC plant is required, Iannucci offers compelling arguments (see Appendix) in favor of a hybrid sensible-chemical storage system. Sensible storage sized at 20 to $24 \mathrm{~h}$ 
would provide nocturnal power as well as charge chemical storage at night. By charging chemical storage $24 \mathrm{~h}$ a day, the size of the chemical reactor can be halved. The reactor size is further decreased by the lesser demands placed on chemical storage: roughly $75 \%$ of storage requirements are met from sensible storage, $25 \%$ from chemical. The sizes of the collector field and receiver are also reduced because storage as a whole is more efficient; baseload output can be maintained with less energy input. Chemical storage is used only when neither direct sunlight nor sensible storage is available. Such an operating mode places a premium on minimizing energy storage costs; chemical systems that do not employ gaseous constituents [such as $\mathrm{CaO}+\mathrm{H}_{2} \mathrm{O}$ $\rightarrow \mathrm{Ca}(\mathrm{OH})_{2}$ ] are thus heavily favored. 


\subsection{THE FUTURE OF CHEMICAL ENERGY STORAGE}

Chemical energy storage has no apparent role whatsoever in the near-term development of solar thermal electric conversion (STEC) plants. Energy storage needs caused by diurnal cycling can be met more economically by sensible storage. Sensible-chemical hybrid storage offers the best potential for the use of chemical energy storage (CES) systems in the long term.

Even this scenario, however, is predicated on several contingencies:

- The number of STEC plants on the grid must be sufficiently large to warrant autonomous operation.

- The winter load must be sufficiently large to require near-baseload performance from all autonomous STEC plants.

- The CES system must be thoroughly integrated with the balance of plant to maximize efficiency.

- Fundamental research must be performed to eliminate substantive questions regarding the suitability of even the best candidate reactions.

Any further work in the area of chemical energy storage for STEC plants should be considered with these qualifications firmly in mind. 


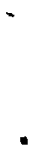




\section{REFERENCES}

Bramlette, T. T. 1979. Thermochemical Energy Storage and Transport Program Progress Report (October 1977-December 1978). SAND-79-8208, Sandia National Laboratory, Livermore, California.

Iannucci, J. J. 1981. The Impacts of Storage upon Solar Plants: General Principles and Seasonal Applications. SAND-80-8242, Sandia National Laboratory, Livermore, California.

Iannucci, J. J., J. D. Fish and T. T. Bramlette. 1979. Review and Assessment of Thermal Energy Storage Systems Based upon Reversible Chemical Reactions. SAND-79-8239, Sandia National Laboratory, Livermore, California.

Nix, R. G. 1982. "Thermochemical Energy Storage and Transport." In Proceedings of the DOE Physical and Chemical Energy Storage Annual Contractors ' Review Meeting, pp. 306-311. CONF-82-0827, U.S. Department of Energy, Washington, D.C.

Smith, R. D. 1979. Chemical Energy Storage for Solar Thermal Conversion. SAND-79-8198, Sandia National Laboratory, Livermore, California.

Stewart, J. 1979. An Assessment of the Use of Chemical Reaction Systems in Electric Utility Applications. EPRI-EM-1094, Electric Power Research Institute, Palo Alto, California. 

APPENDIX

COMBINED CHEMICAL/SENSIBLE STORAGE CONCEPT

FOR SEASONAL APPLICATIONS 
. 


\section{COMBINED CHEMICAL/SENSIBLE STORAGE CONCEPT}

FOR SEASONAL APPLICATIONS

This appendix consists of a verbatim reproduction of a Sandia National

Laboratories-Livermore internal memorandum from Joseph $\mathrm{J}$. Iannucci to William G. Wilson, used with the gracious consent of the author. 
da:e December 8, 1978

10

W. G. Wilson - 8457 .

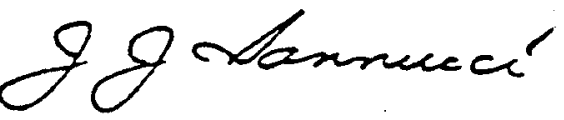

Joseph J. Iannucci

Member of Technical Stalf

(7) Energy Systems Siudies Division

Sandia Laboralories

Livermore, Califorria 94550

Phone $415-422-2140$ FTS $532-2140$

110m. J. J. Iannucci -8326

subjecr Combined Chemical/Sensible Storage Concept for Seasonal Applications

The claims

I have come up with what may be an original concept for the storage subsystem of a seasonally storing plant. Basically, separate sensible and chemical storage units are used at the same plant (either an electric plant or a process heat plant) in a way such that the strengths of each are used to great advantage. I believe this concept will yield busbar energy costs (BBEC) for seasonally storing plants 40 to $50 \%$ of the pure chemical storage BBEC. This is done by decreasing the required field size (Solar Multiple, SM) by perhaps as much as $40 \%$, reducing the chemical reactor size by as much as $80 \%$, with little increase in the energy-related costs of storage. The overall storage efficiency of this plant might be much higher $(80 \%)$ than the pure chemical storage plant. A side benefit (not included in calculations) may be that the sensible storage seoment may serve as a temporary repository for thermal energy which is otherwise discarded from the process stream by the pure chemical storage plant.

I have been considering combined chemical/sensible storage systems for almost two years as a low priority item. Stan Zehr and I first examined the combination in November 1976 but nothing came of this work since we did not have a good grasp of solar thermal storage then. In April 1977 Carl Hiller and I revisited the area briefly, again coming to no conclusion. The work I have done during the last year and a half has finally led me to (what I believe is) the right way of thinking about this coupling sensible and chemical storage.

The Caveats

What this concept does not do is lower the BBEC of seasonal storage below the BBEC for more natural daily storage with sensible heat. Nor does this concept make daily storage with chemical attractive. The comparisons below are between "standard" seasonal chemical storage and the hybrid sensible/ chemical concept. I have used Albuquerque as my reference location; the situation may look less promising for poorer localities. More refined comparisons are needed to nail down more realistic costs and benefits. I have not considered herein the technical feasibility of this hybrid system, (although I see no major obstacle to its implementation) merely the economics of 
coupling sensible and chemical storage in this manner. It is my belief that if chemical storage cannot be made to look economically justified using this concept, it may never look good in any application. This seems to me to be chemical storage's best bet for the future. I send this to your group for review and guidance.

The Concept

Very simply, during the day both sensible and chemical storage systems are charged while providing for the daytime load. Sensible storage is sized at about 20 to 24 hours and the attempt is made to fill it each day. At night, sensible-storage is discharged through the turbine and is used to charce the chemical system. The chemical system is discharged only when "its energy is needed (predominantly in the late fall, winter and early spring) and sensible storage provides for almost all of the purely diurnal needs. I call this "sensibilizing a chemical storage system."

This allows very little energy to be processed by the chemical storage sector. Remember that the total energy from storage over the year is dominated by daily, not seasonal, needs. For example, a baseload plant requires 8760 hours of output over a year; for a $100 \mathrm{MWe}$ plant this is 876000 MWhe. Roughly $40 \%$ of these hours ( 350400 MWhe) can be handled without any storage. Roughly another $45 \%$ ( 394200 Mhe) can be handled with 16 hours of storage. Only the last 15\% (137400 MWe) or so comes from the "seasonal part" of storage. With this hybrid concept, the chemical storage load is reduced from $60 \%$ of these hours (525600 Mhe) to 15\% of these hours (131400 MWhe). Since chemical storage is inefficient roundtrip (say 50\%), reducing the energy which passes through chemical storage is a real energy save (in this case, 394200 Mi'he) and roundtrip efficiency booster (I have assumed sensible to be close to $100 \%$ efficient, the net average efficiency of storage is then roughly $(525600) /(394200+1 / .5131400)=80 \%$ instead of $50 \%$ efficient).

Even larger reductions will be possible in charge rates. First of all, during the charging season the chemical system is charging all day and all night. This reduces the required charge rate by a factor of 2 immediately. Further, only one-fourth as much energy has to get into chemical storage as in the pure chemical case since sensible is used to service nightly needs. To continue this example, previously roughly 229950 Mhe had to get into chemical storage during the 1095 daylight hours (average rate while charging, $210 \mathrm{MW}$ ); with this concept, 131400 MWhe have to get into chemical storage during the 2190 total hours. (average rate, $60 \mathrm{MWe}$ ) leading to a chemical charge rate reduction of $71 \%$.

Larçe size reductions in front end costs will occur. A smaller chemical charge rate will reduce parasitic energy costs proportionately. Further, the higher efficiency of combined chemical/sensible storage will mean less energy collected during the year ( 394200 Whe less) reducing the solar multiple by about $29 \%$ and the receiver by the same amount. 


\section{The Costs}

The costs of seasonal (long term) storage are dominated by three subsystems: collectors, reactors, and storage of chemicals. (While the balance of these subsystem costs may vary from one envisioned reaction sequence to another, these three will always dominate.) Rocket Research and I have both found that seasonal (autonomous) systems optimize out at very large field sizes, receiver sizes, and charge rates. Ballpark solar multiples of 10 , with commensurately large receivers) charge/discharge ratios of 9 or so. As for performance, roundtrip efficiencies of $50 \%$ may even be optimistic. These large sizes are what cause the costs to be so high (obviously). I have gone through a simple sizing exercise to show why they are so large and how my. concept obviates these problems.

Sumiarizing the size (hence cost) reductions of the chemical sector:

$\begin{array}{ll}\text { Charge rate reduced by } & 71 \% \\ \text { Field size reduced by } & 29 \% \\ \text { Receiver size reduced by } 29 \%\end{array}$

These reductions will be especially advantageous with a system such as $\mathrm{Ca}(\mathrm{OH})_{2}$ where the energy-related costs may be quite negligible. This specific reaction is currentily hampered by high charge rate costs.

It remains to be seen how the slight oversizing of the sensible storage section will effect the economics, but traditionally sensible storage plays a small role in the BBEC used for daily cycling $(<10 \%)$. Overall I estimate it may be possible to reduce the BBEC for a seasonally storing plant by 40 to $60 \%$ using this combined chemical/sensible storage concept.

\section{The Conclusions}

This is an interesting concept which I believe deserves either some confirmation of refutation. It seems to have economics and operational flexibility in its favor. The side benefits of continuous endothermic reactor operation and the opportunity to store sensible heat somewhere temporarily may be the key to the whole chemical storage concept. The concept seems to me to be the best use for chemical energy storage.

I am looking forward to your comments (both positive and negative) on this concept. I have tried to objectively lay out the potentialities I see for it. If I can clarify the concept or the calculations, I would be delighted to do so. 
Copy to:

S. W. Zehr, 8313

T. S. Gold, 8320

P. J. Eicker, 8326

M. J. Fish, 8326

J. B. Woodard, 8326

J. B. Hoodard, 8326

R. C. Wayne, 8450

T. T. Bramlette, 8451

T. D. Brumleve, 8457

J. D. Fish, 8451

J. D. Gilson, 8453

R. J. Gallagher, 8453

C. C. Hiller, 8453

W. S. Winters, 8453

J. J. Iannucci, 8326 


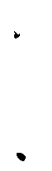




\section{DISTRIBUTION}

No of

Copies

\section{OFFSITE}

US Department of Energy Attn: J. Brogan

Office of Energy Systems Res. Forrestal B1dg, CE-141 5E-052 Washington, DC 20585

US Department of Energy

Attn: I. Gyuk

Office of Energy Systems Res. Forrestal B1dg, CE-141 5E-052 Washington, DC 20585

US Department of Energy

Attn: R. Shivers

Office of Energy Systems Res. Forrestal B1dg, CE-141 5E-052 Washington, DC 20585

27 DOE Technical Information Center

Argonne National Laboratory Solar Thermal Storage Program Attn: A. Michaels Building 362

9700 S. Cass Avenue Argonne, IL 60439

10 Battelle Columbus Labs Attn: J. S. Barnhart 505 King Avenue

Col umbus, $\mathrm{OH} 43201$

Lawrence Berkeley Laboratory

Attn: C. F. Tsang University of California Bldg. 90, Room 1012-H

1 Cyclotron Road Berkeley, CA 94720
No of

Copies

Lawrence Livermore Laboratory

Attn: Tech. Info. Dept, $L-3$

University of California

PO Box 808

Livermore, CA 94550

Charles F. Meyer

1141 Cima Linda Lane

Santa Barbara, CA 93108

Minnesota Geological Survey

Attn: M. Walton

319 15th Avenue S.E.

Minneapol is, MN 55455

New York State Energy Research \& Development Agency

Attn: Gunnar Walmet

Rockefeller Plaza

Albany, NY 12223

Oak Ridge National Laboratory

Attn: J. F. Martin

PO Box $Y$

Oak Ridge, TN 37830

Rocket Research

Attn: L. B. Katter

York Center

Redmond, WA 98052

Sandia Laboratories

Attn: J. J. Iannucci

PO Box 969

Livermore, CA 94550

Sandia Laboratories

Attn: L. Radosevich

PO Box 969

Livermore, CA 94550 
No of

Copies

Sandia Laboratories

Technical Library Div. 3141

A1buquerque, NM 87185

Sandia Laboratories

Attn: William G. Wilson

PO Box 969

Organization 8453

Livermore, CA 94550

Sandia Laboratories

Attn: R. 0. Woods

Organization 4715

A1buquerque, NM 87115

Solar Energy Research Inst.

Attn: Director

1536 Cole Blvd.

Golden, CO 80401

Tennessee Valley Authority

Attn: A. Betbeze

1150 Chestnut, Tower 2

Chattanooga, TN 37401

Tennessee Valley Authority

Energy Research Section

1360 Commerce Union Bank

B1dg.

Chattanooga, TN 37401

TRW Energy Systems Group

Attn: E. Berman

Technical Library

7600 Colshire Drive

McLean, VA 22101

US Army Corps of Engineers

Attn: Library

PO Box 59

Louisville, KY 40202

US Department of Interior

Attn: Natural Resources

Library

Serials Branch (G/E)

Washington, DC 20240
No of

Copies

\section{FOREIGN}

Bengt Hidemark Gosta Danielson

Arkitekter SAR

Attn: A. Boysen

Jarntorget 78

S-11 29 Stockholm

Sweden

Pub1ic Works of Canada

Attn: E. L. Morofsky

C456 Sir Charles Tupper Bldg. Riverside Dr. and Heron Rd.

Ottawa, Ontario

K1A 0M2 Canada

ONSITE

DOE Richland Operations Off.

H. E. Ransom/D. R. Segna

Pacific Northwest Laboratory

L. D. Kannberg (10)

W. W. Laity

J. R. Raymond

Technical Information (5)

Publishing Coordination (2) 